\title{
Decisions in Immunization Policies: A Coalition Between the Public and the Professionals
}

\author{
JOSEPH A. BELLANTI AND VIJAYA L. MELNICK \\ Georgetown University School of Medicine, and the University of the District of \\ Columbia, Washington, D.C., USA
}

In the discussions related to the swine influenza episode, when asked by Senator Edward Kennedy what he (Dr. Ted Cooper) would have done differently if he had to do it over again, Dr. Ted Cooper, then Assistant Secretary of Health, replied that "The most important thing would have been a more comprehensive widespread discussion with all sectors of the public ... so that everybody could understand what the scientific information was and what the anticipated types of problems were".

In an age of skepticism, science has come under severe public scrutiny and question. This is dramatically addressed in the Reports and Recommendations of the recent National Immunization Conferences (3):

"The fortunes of the 1976 swine flu immunization program are a dramatic demonstration that the public health field has not escaped the corrosive effect of the diminished confidence of Americans in established authority and social institutions."

"The public in general, and to an even greater degree specific segments of the population, no longer have the level of quality of trust in the nation's leaders-in the executive branch, in the Congress, or in the medical or business communities-that those groups once enjoyed. The American people apparently feel that they have not been told the whole truth about so many events and issues affecting them that they are more than ever wary of what they are told today by persons occupying high positions".

It is, therefore, not surprising that the public no longer implicitly believes that science and human progress are necessarily synonymous. As DuBridge (1) aptly noted, "Science and technology are no longer separable from political and social problems ... "Some have said that science is too important to get mixed up in politics. The fact is that today science is too important to stay out of politics. For in our democracy, it is through politics that things get done.

The question of immunization that involves large groups of people strikes at the very heart of such public concerns and scientific interest. In recent years, a decrease in rates of immunization to childhood infectious diseases has occurred. This was well documented by the papers of Drs. Sabin and Mortimer in the present Symposium. The factors related to the diminished rates are varied and complex and involve the public, the professionals, and the policy makers. Among the many problems associated with our immunization programs are those attributed to apathy. Although among the Symposium participants there was no consensus as to where and to with whom apathy lies, there was general agreement that the erosion in rates of immunization could be partially atrributed to apathy. Moreover, the question of apathy may involve several groups including the providers, the consumers, the media, as well as federal and local health agencies. Collectively, this has resulted in low levels of immunization, especially among high risk groups such as children who live in economically disadvantaged communities and the elderly who may not have access to immunizations. The current national trends of immunization were described in the present Symposium by Drs. Sabin and Hinman. In recent years, the numbers of
American children inadequately protected against poliomyelitis, diphtheria, and other common infectious diseases has been increased. Although most of these diseases are considered to be only minor health problems in most children, complications arising from them can lead to paralysis, mental retardation, permanent disability, and death. Recent issues surrounding the swine influenza program have further eroded public confidence in immunization programs. The ethical and legal ramifications of these questions were adequately addressed by Drs. Walters and Zimmerly.

The Symposium, "Public Concerns of Immunization", has evolved for the purpose of bringing together the concerned public, professionals, educators, health agencies, as well as representatives from local and federal government, the legal profession, ethicists, manufacturers, and the media - all of whom share in the problem of immunizations. It is appropriate that the proceedings of this Symposium be published as a supplement to Pediatric Research because the problems of immunization not only affect in large measure the pediatric population, but also because of the nature of the problems and constraints affecting infants and children, we need to be in the forefront to try and bridge the communication barrier that presently exists between clinicians, researchers, and the consumers. Although global questions were addressed, we sought to maximize our efforts by seeking participation from individuals primarily from the greater Washington, D.C. area. The Symposium represents a collaborative effort with all of the major universities, medical schools, medical societies in the greater Washington, D.C. area, as well as several of the national professional and voluntary organizations. A distinguished and knowledgeable group of local and national authoritative speakers has assembled in the effort. In this way, the major issues affecting the public are being identified and discussed in an open forum by individuals who were aware of the problems and who could speak effectively to them.

While there was good public attendance, we had hoped for much wider public participation. We feel that this would have been achieved had the media taken a more active and serious role in informing the public regarding the availability of such a forum. We therefore feel it is of vital importance in the success of such symposia that there be established an initial cooperation between the media and the participating groups. Hopefully, this will ensure wide publicity of a forthcoming symposium, but in particular, the availability of a forum to air public concerns and establish an effective dialogue between the public, the professionals, and the policy makers. The media can also provide a dispassionate analysis of the meeting. It is to this end that we invited the participation of the media in general and Ms. Carper and Mr. Boffey as participants in the proceedings.

It has become increasingly apparent that there be a significant and serious involvement of the public in the health care systemnot only as recipients of health, but also as active participants in the formulation of health care policy. Mrs. Newman and Dr. Karzon addressed these issues. The short and not so very happy life history of the national swine influenza program has already 
become a classic health policy case study because the elements of policy and politics were so intertwined. A detailed description of the swine influenza immunization program and its aftermath is found in the recent report by Neustadt and Fineberg (2).

Two national immunization conferences have been held by the Department of Health, Education and Welfare and are examples of how the government is seeking to widen the debate. Further, through their immunization initiative, the HEW is actively addressing the problem of diminished rates of immunization. The complexity of this program was eloquently reviewed by Dr. Schlegel. Groups such as the American Academy of Pediatics and the U.S. National Commission for the International Year of the Child have taken the problem of diminished immunization rates as a major challenge. The present Symposium, sponsored by the Immunology Center of Georgetown University, was intended to further enhance public awareness of the need for and the problems

Copyright ( $) 1979$ International Pediatric Research Foundation, Inc. $0031-3998 / 79 / 1305-672 \$ 02.00 / 0$ associated with immunizations. It fulfills one of the educational objectives of the Center which is to establish frequent dialogues with the public concerning scientific issues related to immunology. We hope that this Symposium served not only as a forum for issues of immunizations, but also as a model which could be used to resolve other questions involving scientists, the professions, and the public.

\section{REFERENCES AND NOTES}

1. Dubridge, L. A.: Science serves society. Science, 164: 1137 (1969).

2. Neustadt, R. E., and Fineberg, H. V.: The Swine Flu Affair, Decision Making on a Slippery Disease. U.S. Department of Health, Education and Welfare (U.S. Government Printing Office, 1978).

3. Reports and Recommendations of the National Immunization Work Groups as submitted to the Office of the Assistant Secretary for Health (March 15, 1977). 